\title{
Salud e Internet: nuevo escenario para la práctica médica
}

\author{
Health and Internet: a new setting for clinical practice
}

Federico García ${ }^{\mathrm{a}}$

\begin{abstract}
Resumen
El autor desarrolla y reflexiona sobre el uso de Internet como fuente de información médica, analizando los beneficios y potenciales perjuicios de este nuevo escenario de práctica médica al que nos enfrentamos los profesionales de la salud.

\section{Abstract}

The author develops and reflects on the use of the Internet as a source of medical information, analyzing the benefits and potential harms of this new setting of medical practice that we face as health professionals.
\end{abstract}

Palabras clave: Internet, Portales del Paciente, Acceso a Internet. Keywords: Internet, Patient Portals, Internet Access.

García F.. Salud e Internet: nuevo escenario para la práctica médica. Evid Actual Pract Ambul. 2019;22(2):e001058.

\section{Salud e Internet}

El uso de Internet como fuente de información médica se ha difundido en las últimas décadas en prácticamente todo el mundo y constituye, en muchos casos, la primera opción para tomar decisiones de índole médica, aunque no siempre la información obtenida sea confiable. La Organización Mundial de la Salud (OMS) señala que sólo el $35 \%$ de la información sobre salud y enfermedades en Internet es realmente valiosa y reconocida por las sociedades científicas.

Los médicos, no podemos dejar de reconocer la irrupción, en los últimos años, del uso de la web como herramienta a la que acuden, cada vez más individuos, de manera espontánea, en busca de información sobre temas vinculados a su salud. Lamentablemente, como sucede con cualquier búsqueda en Internet, la calidad de información obtenida no siempre es la mejor o la más adecuada, lo que puede contribuir a aumentar la confusión, sobre todo en temas vinculados al cuidado de la salud.

Por ejemplo, como lo señala el portal Jano.es, en España, "...el $49 \%$ de los internautas de 16 a 74 años recurrieron al buscador Google en 2016 en busca de asesoramiento médico, según datos de Eurostat, un $30 \%$ más que hace 10 años"1. Este aumento fue similar al documentado en otros países de la Unión Europea, ya que en 2017, ",,el $48 \%$ de los usuarios de internet europeos habían utilizado Google con ese mismo fin, un 29\% más que en $2006^{\prime 1}$. En los EE.UU. se estima que el que el $80 \%$ de los usuarios en ese país han utilizado Internet para indagar sobre temas relacionados con la salud ${ }^{2}$.

Como afirma Tebar, "...el filósofo inglés Francis Bacon, decía que saber es poder y que en el caso de los pacientes, está demostrado que estar bien informado puede mejorar la toma de decisiones sobre sus opciones de tratamiento $y$, por tanto, sus posibilidades de mejora. Sin embargo, la búsqueda de información sobre salud en Internet supone serias dudas en cuanto a la rigurosidad de sus contenidos" ${ }^{3}$.

Este nuevo escenario que se presenta frente a nosotros, merece ser considerado y analizado en profundidad, venciendo una primera negación y prejuicios, incluso acerca de la pertinencia o no de contestar consultas médicas vía Internet, sin tener un contacto directo con el paciente y careciendo del imprescindible examen físico a la hora de arribar a un diagnóstico certero.

Considero que es nuestro deber, como médicos, conocer y comprometernos con este escenario, pudiendo ofrecer a la comunidad sitios confiables, que brinden información de alta calidad académica y acorde a la evidencia científica, sin intereses económicos ni compromisos con la industria farmacológica de ningún tipo.
Probablemente la mejor forma de prevención es la educación, e Internet se ha convertido en un canal de comunicación de insospechada importancia para la educación sanitaria, permitiendo una mayor accesibilidad a la atención médica, superando barreras que tienen que ver con la distancia, los horarios o los tiempos de espera.

En medicina es frecuente escuchar hablar de la "oportunidad perdida", ya sea por falta de tiempo en la consulta, por pudor o vergüenza del paciente o porque no surgió la duda en el momento adecuado, por el miedo o la ansiedad que genera la consulta médica. La falta de habilidad de los médicos para generar el espacio y el tiempo necesario para que el paciente pueda agotar sus dudas e interpretar correctamente el mensaje que intentamos transmitir, contribuye en cierto modo a la necesidad del paciente de recurrir a otras fuentes de conocimientos e información.

Dentro de este contexto, consideramos las consultas en la web, como una "oportunidad recuperada", donde las personas podrían repreguntar o consultar sobre temas que no habían logrado terminar de interpretar y comprender o que surgían de manera inesperada. Una oportunidad recuperada de realizar acciones concretas de prevención, educación y promoción de la salud.

Es imprescindible entender que las consultas realizadas en línea no reemplazan la consulta médica tradicional, y deben ser interpretadas sólo como un complemento de ésta, con recursos y contenidos que le son propios para brindar una orientación médica. Este concepto debe ser comprendido plenamente por el usuario de esta modalidad de abordaje. Debe entenderse que la consulta es de carácter orientativa y no reemplaza la consulta médica tradicional. Hablamos de orientación, de oportunidad recuperada, de complemento, y de ninguna manera de reemplazar con esta modalidad la consulta médica tradicional.

El mundo no es el mismo antes y después de Internet, ni desde el punto de vista comercial, ni en la manera de conocer y comunicar. Sin embargo, la sobreabundancia de información no siempre garantiza su calidad.

\section{¿Qué opinamos y como nos sentimos los médicos con este fenómeno? ¿Es Internet un tercero en discor- dia entre nosotros y el paciente?}

Consideramos que la web representa un gran desafío para los médicos, nos obliga a estar bien informados y a aceptar dejar de lado nuestro rol de "poseedores" del conocimiento para empezar a compartir dicho rol con el paciente. También él es capaz de investigar, de informarse y acceder a diferentes alternativas y modalidades para encarar su dolencia o el cuidado de su salud. El paciente adquiere protagonismo y mayor participación en la

a Servicio de Medicina Familiar y Comunitaria, Hospital Italiano de Buenos Aires. 
toma de decisiones con respecto a que conducta es la más adecuada.

Es evidente que tanto los médicos como los pacientes en general nos encontramos frente a un nuevo escenario y no podemos mantenernos ajenos a esta realidad. Debemos intentar convertirla en un escenario favorable, que sume elementos para mejorar la calidad de la relación médico paciente, que aumente la posibilidad de educación sanitaria y facilite una mayor y más responsable toma de decisiones compartidas entre el médico y el paciente en lo referente al cuidado de su salud.
Observamos que la consulta médica tradicional podría ser insuficiente para agotar las dudas y la información que necesitaba el paciente. ¿Podría obedecer a una duración insuficiente de la consulta programada, a la falta de empatía o a una insatisfactoria relación médico-paciente? Seguramente son múltiples los factores que influyen y determinan que el paciente busque fuentes alternativas de información, siendo Internet la más utilizada.

La accesibilidad que representa esta modalidad, la convierte en un recurso de privilegio para saciar la necesidad de respuesta rápida en una sociedad signada por la inmediatez.

\section{References}

1. La búsqueda de información médica en internet aumenta en España en un $30 \%$ en 10 años; 2017. Available from: https://www.jano.es/noticia-labusqueda-informacion-medica-internet-27739 [Last access: 01-03-2019].

2. Sadasivam RS, Kinney RL, Lemon SC, Shimada SL, Allison JJ, Houston TK. Internet health information seeking is a team sport: analysis of the Pew Internet Survey. Int J Med Inform. 2013;82(3):193-200. Available from: 10.1016/j.ijmedinf.2012.09.008.

3. Martínez-Tebar L. Salud en internet, ¿cómo buscar información con rigor?; 2018. Available from: https://www.efesalud.com/salud-en-internet-comobuscar-informacion [Last access: 01-03-2019]. 